\title{
Phase Behavior and Interchange Reactions in Poly(butylene terephthalate)/Poly(ester-carbonate) Blends
}

\author{
Jose Luis Rodríguez, Jose Ignacio Eguiazábal, and Jon NazÁbal
}

Departamento de Ciencia y Tecnología de Polimeros, Facultad de Quimica (UPV/EHU), P.O. Box 1072, San Sebastian, Spain

(Received October 2, 1995)

\begin{abstract}
The phase behavior and the interchange reactions in binary blends composed of poly(butylene terephthalate) (PBT) and two poly(ester-carbonate) (PEC) copolymers were studied by differential scanning calorimetry (DSC). Results of thermal transitions of the blends indicated that the miscibility level depends on the preparation method used. Melt-mixed and precipitated blends appeared monophasic, while those prepared by casting were phase separated. Interchange reactions progressively developed in the blends when they were maintained in the melt state for increasing periods of time.

KEY WORDS Poly(butylene terephthalate)/ Poly(ester-carbonate)/Blends / Miscibility / Interchange Reactions / Calorimetry /
\end{abstract}

Polymer blends are at present one of the most active investigation fields in polymer science and technology. This is a consequence, among other reasons, of the possibility to select a desired combination of the properties of the blend constituents provided by these polymeric systems.

Polyester blends have been extensively studied by a great number of investigators. ${ }^{1,2}$ Different miscibility and property levels have been found for these blends. Moreover, interchange reactions and their effect on phase behavior and properties of the blends have been analyzed in some cases. Among the second components, the most relevant are other polyesters, polycarbonates, polyamides, and the poly(hydroxy ether of bisphenol A). ${ }^{1,2}$

Poly(butylene terephthalate) (PBT) is an engineering semicrystalline polyester with a broad range of performance characteristics, such as high heat resistance, strength and toughness, chemical and water resistance and lubricity, among others. It is used in practically all materials-consuming industries.

Poly(ester-carbonate) (PEC) copolymers are thermoplastic amorphous materials obtained generally by polycondensation of bisphenol $\mathrm{A}$ and derivatives of isophthalic and terephthalic acids and carbonic acid derivatives. ${ }^{3}$ As a consequence of copolycondensation, the following chemical structure is obtained:

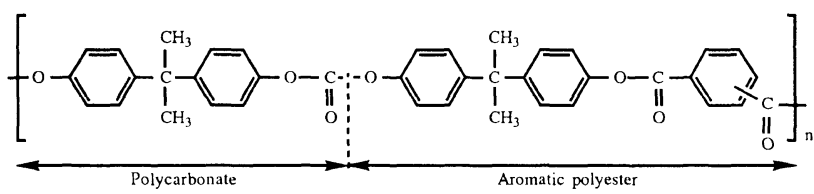

These materials may be consequently considered as copolymers of bisphenol A polycarbonate and the polyarylate of bisphenol $\mathrm{A}$ and isophthalic/terephthalic acids. They show a set of properties similar to that exhibited by bisphenol A polycarbonate, with the exception of a higher thermal stability due to the presence of the more rigid aromatic ester units. This thermal stability increases as the content of aromatic ester units in the copolymer increases.

The importance of the blends of PBT with both of the components of the PEC is proved by the extensive investigation on blends composed of PBT and bisphenol A polycarbonate ${ }^{4-25}$ or the polyarylate of bisphenol $\mathrm{A}$ and 50/50 isophthalic/terephthalic acids. ${ }^{26-36}$ Blends of PBT with another polyarylate of a different composition have been also studied. ${ }^{37-40}$ PBT/bisphenol A polycarbonate blends have been characterized as partially miscible, while PBT/polyarylate blends are totally miscible. The existence of interchange reactions between blend components in both PBT-based systems has also been demonstrated. Moreover, ternary blends of polyarylate/polycarbonate/PBT have been found to be monophasic or biphasic depending on the content of the three polymers in the blends. ${ }^{41}$

Blends of poly(ethylene terephthalate) with PEC copolymers composed of $1: 2$ terephthalic and bisphenol $A$ residues linked by ester and carbonate linkages have been studied by Aharoni. ${ }^{42,43}$ Patents refering to blends of PEC with poly(alkylene terephthalates) have been registered. ${ }^{44,45}$ However, to our knowledge, no systematic study has been carried out on the phase behavior, interchange reactions and properties of PBT/PEC blends. Hence, in this work, we have carried out a study of the phase behavior and the interchange reactions by DSC in blends comprising PBT and two PEC copolymers of different compositions, and prepared by different methods. In a following paper we will analyze the properties of these blends.

\section{EXPERIMENTAL}

The polymers used in this work were commercial products. PBT was Arnite T06-200 (Akzo) and was supplied by La Seda de Barcelona, S.A. (Spain). Its number-average molecular weight, determined by viscosimetry in a phenol-tetrachloroethane $(60: 40)$ mixture at $25^{\circ} \mathrm{C}$, using the equation ${ }^{46}$.

$$
[\eta]=2.15 \times 10^{-4} M_{n}^{0.82}\left(\mathrm{dL} \mathrm{g}^{-1}\right),
$$

was 28400 . The PEC copolymers were kindly supplied by Bayer Hispania, S.A. (Barcelona, Spain) under the trade names APEC 9306 and APEC 9310. They will be called respectively PEC-C and PEC-E. The composition of the PEC copolymers used in this work was determined 
by FTIR spectroscopy (Nicolet 5DXC), using the carbonyl absorption bands of the carbonate group (which appears approximately at $1775 \mathrm{~cm}^{-1}$ ) and of the aromatic ester group (at $1740 \mathrm{~cm}^{-1}$ ). A calibration curve was constructed by recording the FTIR spectra of films of bisphenol A polycarbonate/polyarylate mixtures prepared by casting from chloroform solutions with compositions covering the whole range between pure polycarbonate and pure polyarylate. The calibration curve was a plot of the ratio between absorbances of the carbonate and ester groups, against the composition of the mixture. From the spectra obtained for films of PEC copolymers, it was found that PEC-C has approximately $42 \%$ aromatic ester groups, so that carbonate groups form the majority, while PEC-E contains $70 \%$ aromatic ester groups. The intrinsic viscosities of the copolymers, measured in THF at $25^{\circ} \mathrm{C}$, were $[\eta]=0.546 \mathrm{dL} \mathrm{g}^{-1}$ and $[\eta]=0.551 \mathrm{dL} \mathrm{g}^{-1}$ for PEC-C and PEC-E respectively.

$\mathrm{PBT} / \mathrm{PEC}$ blends in all the composition range were obtained by melt mixing in a Brabender mixing head. Blend components were previously dried in vacuo at $80^{\circ} \mathrm{C}$ for 24 hours to prevent degradation reactions caused by moisture. Blending was carried out at $250^{\circ} \mathrm{C}$ and $30 \mathrm{rpm}$ for $12 \mathrm{~min}$, the time at which a steady torque was obtained. The blends were subsequently compression molded at $250^{\circ} \mathrm{C}$, using a Schwabenthan Polystat $200 \mathrm{~T}$ press. After molding, the sheets (thickness: $1 \mathrm{~mm}$ ) were immediately immersed in cold water.

PBT/PEC blends were also obtained, both by casting from solutions of both components in adequate proportions in 1,1,1,3,3,3-hexafluoro-2-propanol (HFP), and by a solution/precipitation method in phenol/methanol. The films and precipitates obtained in each case were dried in vacuo at $80^{\circ} \mathrm{C}$ for 48 hours.

Calorimetric analyses as well as interchange reactions in the blends were performed in a Perkin-Elmer DSC 7 calorimeter. Heating scans were carried out at a scan rate of $20^{\circ} \mathrm{C} \mathrm{min}^{-1}$, under a nitrogen atmosphere. The glass transition $\left(T_{\mathrm{g}}\right)$, crystallization and melting temperatures ( $T_{\mathrm{c}}$ and $T_{\mathrm{m}}$ respectively) as well as the crystallization and melting heats $\left(\Delta H_{\mathrm{c}}\right.$ and $\Delta H_{\mathrm{m}}$ respectively) were obtained in the usual way. All transitions were determined from the second scan. A first scan was carried out from $10^{\circ} \mathrm{C}$ to $250^{\circ} \mathrm{C}$, followed by cooling to $10^{\circ} \mathrm{C}$ at approximately $100^{\circ} \mathrm{C} \mathrm{min}^{-1}$. This was made in order to homogenize the thermal histories of the samples to make possible the comparison between the results obtained. When interchange reactions were studied on precipitated samples, the thermal treatments in the melt state were carried out between the first and second scans.

\section{RESULTS AND DISCUSSION}

\section{Melt Mixed Blends}

Transparency was the first text made of the miscibility of the blends. All melt-mixed blends were transparent in the melt state, irrespective of the type of PEC copolymer and of the blend composition. In the solid state, PEC and PEC-rich blends were transparent, while PBT and PBT-rich blends were opaque, probably due to crystallinity. The transparency of solid PEC-rich blends and that observed in the melt for all compositions, point to the miscibility of both PBT/PEC systems studied in this

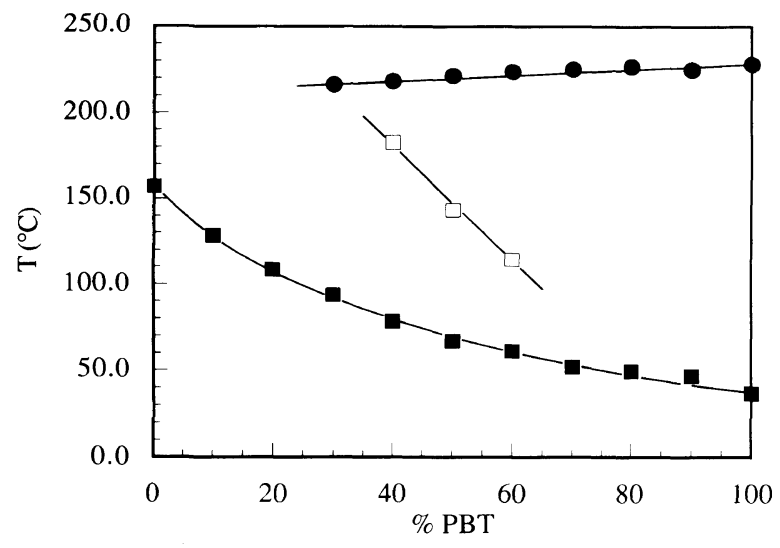

Figure 1. Thermal transitions of melt-mixed PBT/PEC-C blends. $T_{\mathrm{g}} ;(\square) T_{\mathrm{c}} ;(\bigcirc) T_{\mathrm{m}}$.

work.

Calorimetric analysis (DSC) was used to analyze the phase behavior of the blends. The results obtained in the second scan for the melt-mixed PBT/PEC-C blends are shown in Figure 1. PBT/PEC-E blends gave very similar plots with the only difference of slightly higher (10 to $\left.20^{\circ} \mathrm{C}\right) T_{\mathrm{g}} \mathrm{s}$ on the PEC-rich side. As can be seen, the $T_{\mathrm{g}}$, intermediate between those of the pure components, indicates the existence of a single amorphous phase and miscibility in both systems.

With respect to the crystallization-melting behavior of the blends, also seen in Figure 1, only the blends of intermediate compositions show a crystallization exotherm whose $T_{\mathrm{c}}$ increased clearly with the decrease in the PBT content in the blends. Finally, the melting endotherm of PBT appeared for blends with PBT contents equal to or higher than $30 \%$. The $T_{\mathrm{m}}$ decreased as the PBT content in the blend decreased, as expected for a miscible blend. A small additional exotherm, with an associated enthalpy lower in all cases than $1 \mathrm{~J} \mathrm{~g}^{-1}$, appeared before the main melting peak in the case of blends with a PBT content greater than $60 \%$. This exotherm may be attributed, following previous works, ${ }^{30}$ to the existence of melting-recrystallization processes in PBT during the calorimetric scan. These processes may take place only at high PBT contents; thus, as the PEC content in the blend increases, recrystallization is hindered, and the exotherm dissappears.

This crystallization-melting behavior may be explained on the basis of the nature of the blends, as deduced from the $T_{\mathrm{g}} \mathrm{s}$, and of the effect of PEC on the crystallization of PBT. At high PBT contents, PBT is able to totally crystallize during cooling in the calorimeter between the first and the second scans. At intermediate compositions, PBT does not crystallize totally during cooling and a fraction of the polymer crystallizes during the calorimetric scan, giving rise to the observed main exotherm. At low PBT contents, PEC makes the crystallization more difficult, hence, the PBT is unable to crystallize either during the cooling or during the heating scan.

This is confirmed by the representations of the $\Delta H_{\mathrm{c}}$ and $\Delta H_{\mathrm{m}}$ against the blend composition, which are shown in Figure 2. The behavior of melt-mixed PBT/PEC-E blends was similar. At high PBT contents, the measured $\Delta H_{\mathrm{m}}$ corresponds to PBT crystallized during cooling because $\Delta H_{\mathrm{c}} \cong 0$, while at very low PBT concentrations, 


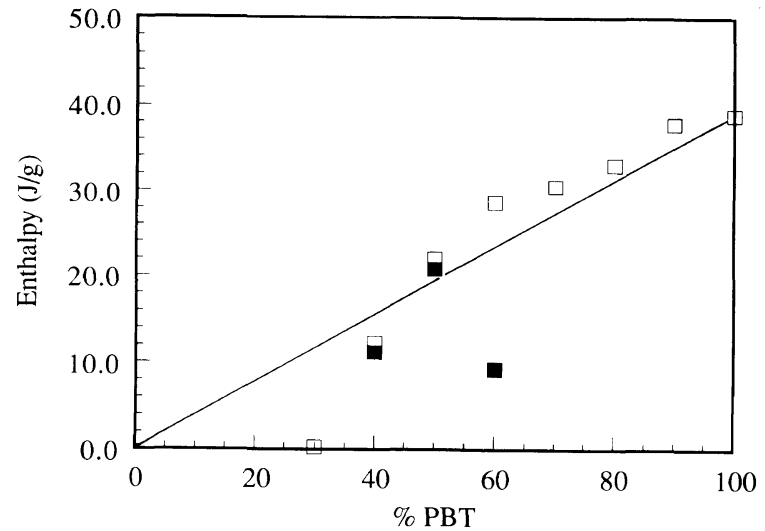

Figure 2. Crystallization and melting heats of melt-mixed PBT/PECC blends. ( $\square$ ) melting heat; $(\square)$ crystallization heat.

the $\Delta H_{\mathrm{m}}$ is zero. At intermediate compositions, the difference $\Delta H_{\mathrm{m}}-\Delta H_{\mathrm{c}}$ indicates the PBT fraction that crystallizes during cooling before the second calorimetric scan. As observed, leaving aside PBT and PBT-rich blends that do not crystallize during heating, this difference is clearly higher for the $60 / 40$ blend, indicating that PBT is also able to crystallize appreciably during cooling at this composition. On the contrary, the $50 / 50$ and $40 / 60$ compositions are practically unable to crystallize during cooling, so they are obtained in an almost amorphous state. In the case of the 30/70 composition, a very small melting endotherm is observed, whereas the crystallization exotherm is not. Crystallization probably takes place during cooling.

As can also be seen, the $\Delta H_{\mathrm{m}}$-composition plot shows values somewhat higher than the additive ones at high PBT contents but lower at PBT contents lower than $50 \%$. Thus, a small favorable effect of PEC on the PBT crystallization appears at high PBT contents, similar to that found by Porter et al. in PBT/polyarylate blends. ${ }^{26}$ At low PBT contents, however, crystallization is hindered.

This set of results points to miscibility in the meltmixed blends. However, it is known that melt processing of polyester blends may give rise to the appearance of block or random copolymers formed by interchange reactions between the components. Consequently, DSC results can lead to erroneous conclusions, so that the existence of interchange reactions was tested.

In a first attempt to check the existence of interchange reactions in the blends, solubility tests were carried out, using chloroform as selective solvent. PBT is insoluble in chloroform, while PEC copolymers are soluble. In Figure 3 we show the insoluble fraction in chloroform of PBT/PEC blends, that should correspond to the PBT content, as a function of the composition. As it is shown, insolubility is always greater than that expected for unreacted blends. This indicates that interchange reactions have taken place during processing. According to previous results ${ }^{6,47}$ only block copolymers are obtained as a consequence of reactions, that is, reactions are at the first stages. Provided that the unreacted blends were not miscible, these block copolymers are expected to exhibit better mutual miscibility than the unreacted components $^{48}$ and could be the reason for the observed transparency and single $T_{\mathrm{g}} \mathrm{s}$. In order to gain insight into

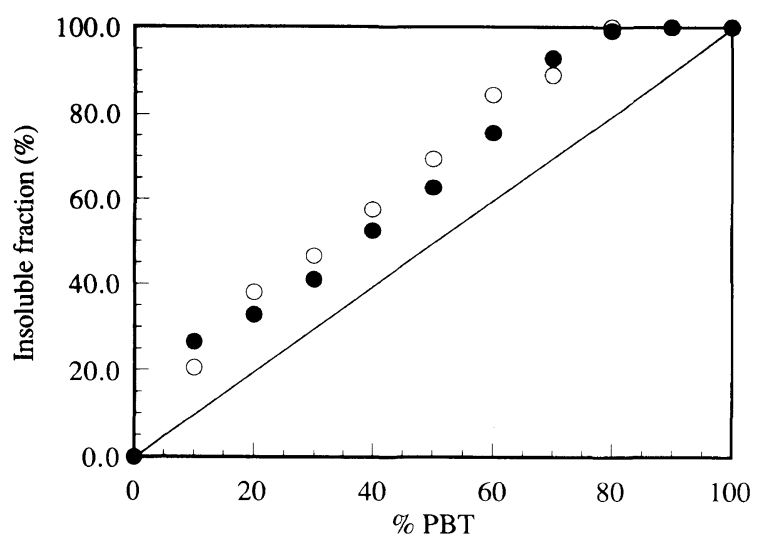

Figure 3. Insoluble fraction in chloroform of PBT/PEC blends. $(O)$ PBT/PEC-C; (O) PBT/PEC-E.

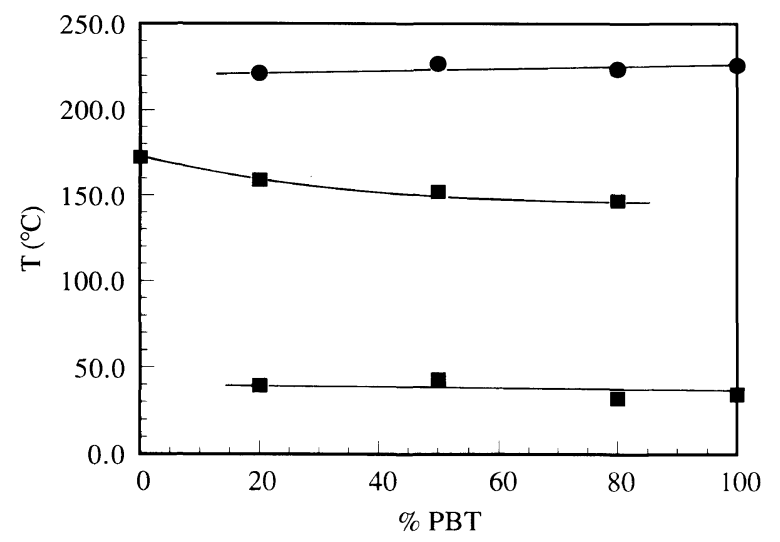

Figure 4. Thermal transitions of PBT/PEC-E blends obtained by casting from HFP solutions. (ם) $T_{\mathrm{g}}$; (O) $T_{\mathrm{m}}$.

the miscibility of the blends, they were also obtained by the most widely used research solution blending method, i.e., casting, to avoid interchange reactions.

\section{Casting and Solution-Precipitation Mixed Blends}

Results of calorimetric analyses of cast blends from HFP solutions are shown in Figure 4 for PBT/PEC-E blends. As can be seen, two clear $T_{\mathrm{g}} \mathrm{s}$ appeared; the low $T_{\mathrm{g}}$ is fairly constant while the upper $T_{\mathrm{g}}$ decreased with respect to that of the pure $\mathrm{PEC}$ as the $\mathrm{PBT}$ content in the blend increased. In PBT/PEC-C blends two $T_{\mathrm{g}} \mathrm{s}$ practically constant and similar to those of the pure components were seen.

These results prove the existence of two phases in these PBT/PEC-C and PBT/PEC-E systems. The partial miscibility of PEC-E blends may be attributed to their greater content of aromatic ester units of the polyarylate, which is miscible with $\mathrm{PBT},{ }^{26}$ while polycarbonate is only partially miscible. ${ }^{4}$

The crystallization-melting behavior confirmed the biphasic nature of these blends. As observed in Figure 4 (PBT/PEC-C results were very similar) no crystallization exotherms appeared because the PBT was fully crystallized during cooling, due to the almost complete absence of PEC in the PBT phase. However, the melting endotherm appeared in pure PBT and in all blends as did the premelting exotherm. The decrease of this exotherm with increasing PEC contents was smaller than in melt-mixed blends also because of the absence of PEC. 


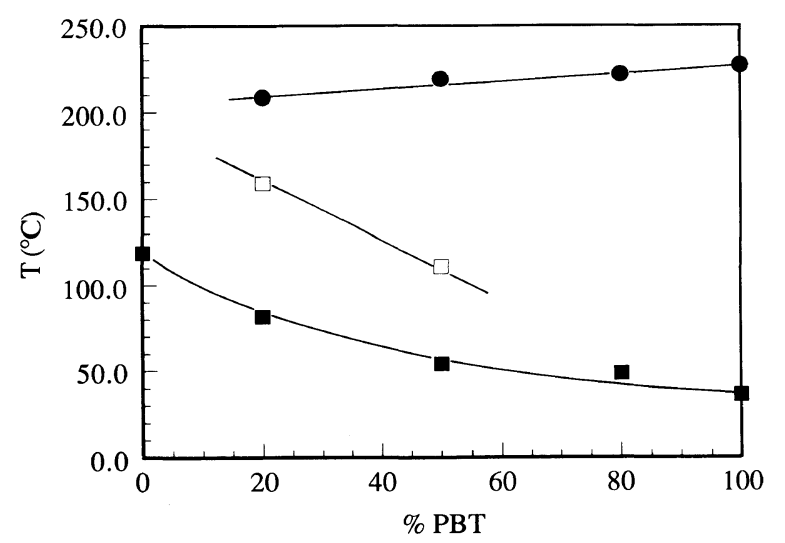

Figure 5. Thermal transitions of PBT/PEC-C blends prepared by solution-precipitation. (口) $T_{\mathrm{g}} ;(\square) T_{\mathrm{c}} ;(\bigcirc) T_{\mathrm{m}}$.

Finally, the $\Delta H_{\mathrm{m}}$ of PBT was practically proportional to blend composition. All these results agree with the $T_{\mathrm{g}}$ results and are clear evidence of the almost complete phase separation that exists in the blends after casting.

This different calorimetric behavior of the cast blends may be due to i) immiscibility, but presence of copolymers from interchange reactions in the melt state that will homogenize the immiscible blends; or ii) miscibility, and perhaps reactions in the melt state, but the process of blending by solution leading to anomalous miscibility results ${ }^{49}$ depending on the phase diagram of the polymer/solvent system. Hence, an additional blending method, solution/precipitation, was also used.

In Figure 5 we show the thermal transitions obtained in the second calorimetric scan for PBT/PEC-C blends prepared by solution solution/precipitation. Very similar results were obtained in PBT/PEC-E blends. As observed in Figure 5, a single glass transition which varies monotonously with blend composition is obtained for all compositions. This indicates that the precipitated blends are miscible at a macroscopic level, since the conditions are not able to give rise to interchange reactions.

The rest of the calorimetric results agree with this explanation because, with the increase in PEC content, the $T_{\mathrm{c}}$ increased and the $T_{\mathrm{m}} \mathrm{s}$ decreased. The $T_{\mathrm{g}}$ of pure PEC-C and those of the 20/80 and 50/50 blends are lower than those obtained in the case of melt-processed materials probably because of the residual phenol. A similar but less pronounced effect was observed for pure PEC-C obtained by casting. Phenol was strongly associated to the polymer, because the $T_{\mathrm{g}}$ did not change after successive calorimetric scans using sample pans with holes. Thus, the $T_{\mathrm{g}}$ values only indicate miscibility qualitatively.

Figure 6 shows the $\Delta H_{\mathrm{c}}$ and $\Delta H_{\mathrm{m}}$ of precipitated PBT/PEC-C blends against composition. The plots of the PBT/PEC-E blends were similar, the only difference being that in the $20 / 80$ composition no peaks appeared, probably due to the greater interactions as a consequence of the higher content of aromatic ester units. In the PBT/PEC-C system, only the 50/50 and 20/80 blends show a crystallization exotherm with a very small crystallization heat for the $50 / 50$ composition. This indicates difficult crystallization in accord with the miscibility level; that is, more crystallization during the

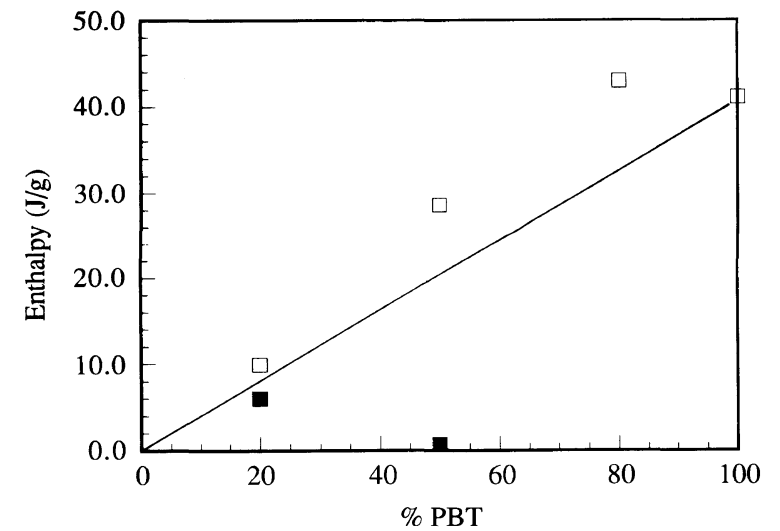

Figure 6. Melting ( $\square$ ) and crystallization ( $\square$ ) heats for PBT/PEC-C blends obtained by solution-precipitation.

scan than in fully crystallized blends by casting, but less than in melt-mixed blends where the $(20 / 80)$ blend was unable to crystallize due to its reacted nature.

The $\Delta H_{\mathrm{m}}$ shows a behavior similar to that of meltmixed blends, although the positive deviation from the additive values is more important, showing a $\Delta H_{\mathrm{m}}$ absolute maximum. This confirms the existence of a favorable effect of PEC on crystallization that is not so clear in melt-mixed blends, probably due to the interchange reactions.

Thus, all the calorimetric results clearly indicate that both PBT/PEC-C and PBT/PEC-E blends are miscible at all compositions. The behavior displayed by casting-mixed blends is explained on the basis of the formation of phase separated ternary PBT/PEC/HFP solutions. On solvent evaporation, miscibilization is kinetically hindered and, consequently, phase separated binary blends are obtained. Finally, the single $T_{\mathrm{g}}$ after melt blending is a consequence of the concomitant effects of both miscibility and interchange reactions. The effect of these reactions on the thermal properties will be followed in the next section in the case of the $50 / 50$ blends.

\section{Interchange Reactions}

Figure $7 \mathrm{a}$ shows the thermal transitions and Figure 8a the $\Delta H_{\mathrm{c}}$ and $\Delta H_{\mathrm{m}}$ of the precipitated 50/50 PBT/PEC-E blend as a function of the time in the melt at $250^{\circ} \mathrm{C}$. As observed, the $T_{\mathrm{g}}$ shows a slight tendency to increase with time, probably due to interchange reactions. ${ }^{26}$ The initial increase in $T_{\mathrm{c}}$ and the decrease in $T_{\mathrm{m}}$ show the difficulties for the PBT crystallization due to the copolymers formed by interchange reactions. ${ }^{50,51}$ The effect is not very important until a treatment time of $20 \mathrm{~min}$, where the drastic decrease in both $\Delta H_{\mathrm{c}}$ and $\Delta H_{\mathrm{m}}$ indicates that crystallization is strongly hindered, probably due to the formation of copolymers with many short PBT sequences.

In the case of PBT/PEC-C (50/50) blends, Figures $7 \mathrm{~b}$ and $8 \mathrm{~b}$, the $T_{\mathrm{g}}$ shows a slight tendency to increase at small reaction times, and to decrease as the time approaches $60 \mathrm{~min}$. The increase in $T_{\mathrm{g}}$ is probably due to interchange reactions and the decrease at high times to degradation of the blends that was also seen in other blends containing condensation polymers. ${ }^{36,51}$

With respect to the crystallization-melting behavior of the PBT/PEC-C blend, an increase in $T_{\mathrm{c}}$ and a decrease 

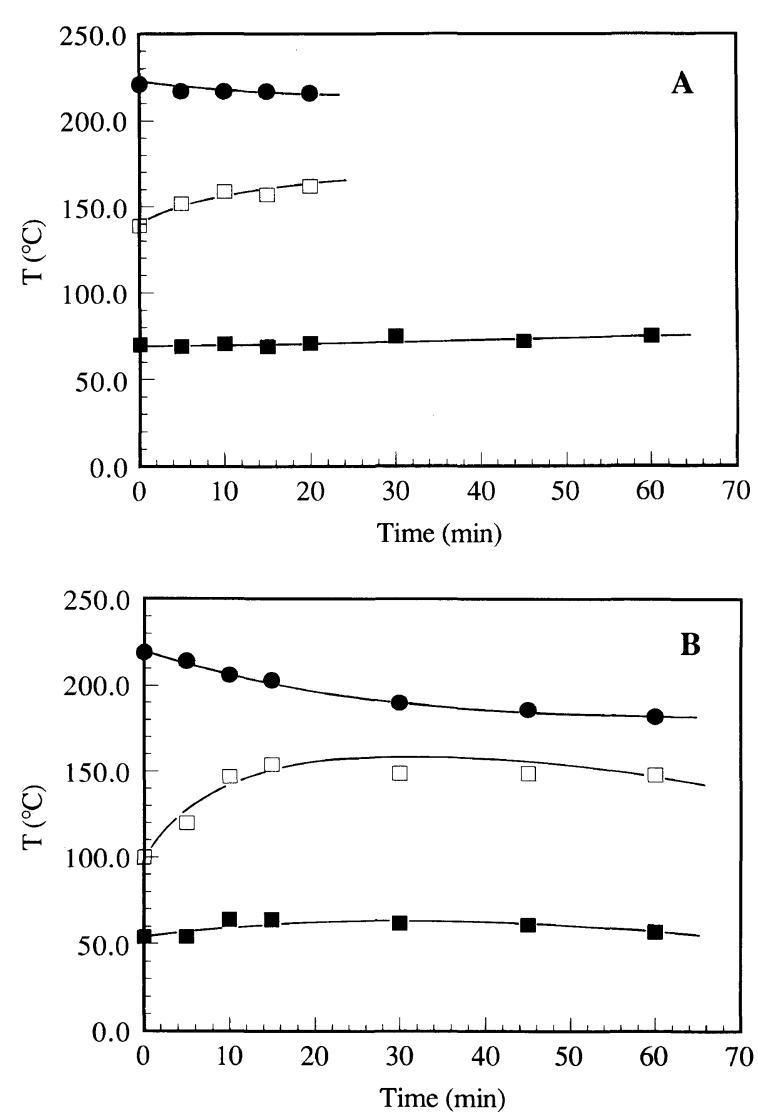

Figure 7. Effect of thermal treatment time at $250^{\circ} \mathrm{C}$ on the therma transitions of precipitated PBT/PEC-E $(50 / 50)$ blends (A) and

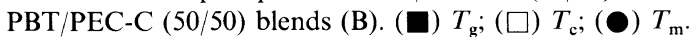
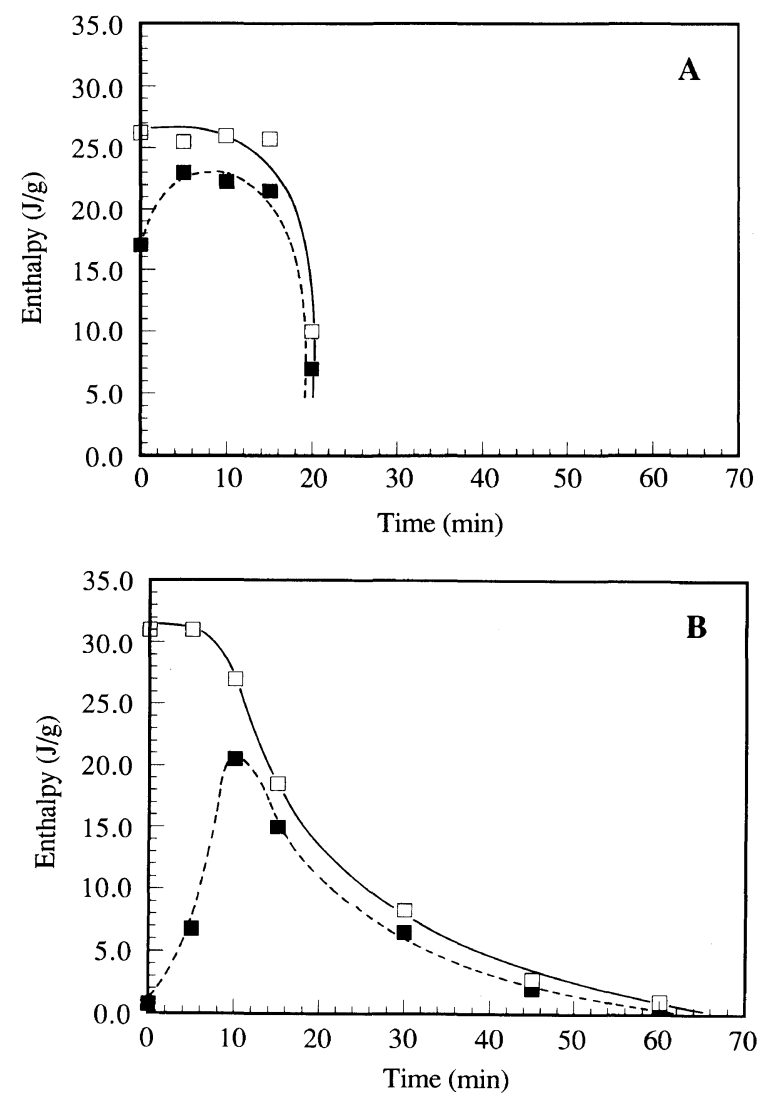

Figure 8. Effect of thermal treatment time at $250^{\circ} \mathrm{C}$ on the crystallization ( $\square$ ) and melting $(\square)$ heats of precipitated PBT/PEC $(50 / 50)$ blends. (A) PBT/PEC-E; (B) PET/PEC-C. in $T_{\mathrm{m}}$ are observed with increasing treatment time, clear consequences of the production of copolymers by chemical reactions. Comparing Figures $7 \mathrm{a}$ and $8 \mathrm{a}$ with Figures $7 \mathrm{~b}$ and $8 \mathrm{~b}$, it can be seen that in the untreated PBT/PEC-C blend, PBT crystallized almost totally during cooling as seen because of the very low $\Delta H_{\mathrm{c}}$, but that in the untreated PBT/PEC-E blend, only partial crystallization took place. This was probably due to the already commented smaller interactions in the PEC-C blends and the subsequent smaller hindrance for crystallization. After 5 and $10 \mathrm{~min}$ treatment times, the $\Delta H_{\mathrm{c}}$ increased in both PEC's, indicating that incomplete crystallization took place during cooling. At times greater than $15 \mathrm{~min}, \Delta H_{\mathrm{c}}$ of the PEC-E blend decreased suddenly. However, in the PEC-C blend, it showed a progressive decrease parallel to that of the $\Delta H_{\mathrm{m}}$, which showed a gradual decrease and appeared always slightly higher than $\Delta H_{\mathrm{c}}$. This different behavior does not seem to be due to degradation, since when the more stable ester structure of the polyarylate ${ }^{52}$ was in the majority, was when the effect was observed to be faster. Thus, the effect seems to be due to a higher reactivity of the ester groups of PEC-E. This higher reactivity might have been corroborated comparing blends of $\mathrm{PC}$ and $\mathrm{PAr}$ with another second polyester, but the different miscibility level impeded this.

Thus, the effects of interchange reactions on the crystallization-melting behavior are progressive in the 50/50 PBT/PEC-C blend and probably at other compositions, in opposition to the behavior displayed by the PBT/PEC-E blend. The reactions hinder crystallization as seen by the increase in $T_{\mathrm{c}}$, and produce less crystalline blends and less perfect PBT crystals. Finally, the earlier effect of reactions in the PEC-E blend indicates a higher reactivity of the majority ester groups of the PEC-E.

\section{CONCLUSIONS}

Blends composed of PBT and two poly(ester-carbonate) copolymers of different compositions show different phase behaviors depending on the mixing method. Melt-mixed blends appear as monophasic partially transesterified materials by DSC and solubility tests and show the hindrance for the PBT crystallization imposed by the reacted copolymers.

Blends prepared by casting in HFP phase separated, probably due to the presence of phase separated ternary solutions in which miscibilization is kinetically hindered on solvent evaporation. Blends obtained by solution-precipitation, however, are miscible, as demonstrated by the appearance of a single $T_{\mathrm{g}}$ in the studied compositions.

The crystallization of PBT during cooling is hindered by the presence of PEC. Hindrance is a function of both miscibility and reaction levels. Thus, the effect is smaller in precipitated blends as compared to that found in melt-mixed blends and does not take place in the phase separated casting blends.

The maintenance of the precipitated blends in the melt state produces interchange reactions, the extent of which depends on the type of PEC copolymer. These reactions hinder crystallization, drastically in PBT/PEC-E after $20 \mathrm{~min}$ at $250^{\circ} \mathrm{C}$ and more gradually in the case of 


\section{PBT/PEC-C.}

Acknowledgments. The financial support of the University of the Basque Country (Project n. UPV 203.215-EA 159/93) is gratefully acknowledged.

\section{REFERENCES}

I. R. S. Porter, J. M. Jonza, M. Kimura, C. R. Desper, and E. R. George, Polym. Eng. Sci., 29, 55 (1989).

2. R. S. Porter and L.-H. Wang, Polymer, 33, 2019 (1992).

3. D. Rathman, Plast. Univ., 32, 161 (1988).

4. D. C. Wahrmund, D. R. Paul, and J. W. Barlow, J. Appl. Polym. Sci., 22, 2155 (1978).

5. R. S. Halder, M. Joshi, and A. Misra, J. Appl. Polym. Sci., 39, 1251 (1990).

6. J. Devaux, P. Godard, and J. P. Mercier, Polym. Eng. Sci., 22, 229 (1982)

7. S. Y. Hobb, M. E. J. Dekkers, and V. H. Watkins, J. Mater. Sci., 23, 1219 (1988).

8. A. W. Birley and X. Y. Chen, Br. Polym. J., 17, 297 (1985).

9. L. A. Utracki, in "Rheological Measurement," A. A. Colyer and D. W. Clegg, Ed., Elsevier, London, 1988.

10. L. A. Utracki, Polym. Eng. Sci., 23, 602 (1983).

11. J. Devaux, P. Godard, and J. P. Mercier, J. Polym. Sci., Polym. Phys. Ed., 20, 1875 (1982); ibid., 20, 1895 (1982); ibid., 20, 1901 (1982); J. Devaux, P. Godard, J. P. Mercier, R. Touillaux, and J. M. Dereppe, ibid., 20, 1881 (1982).

12. L. A. Utracki, "Polymer Alloys and Blends," Hanser, Munich, 1990, Chapter 3.

13. W. N. Kim and C. M. Burns, Makromol. Chem., 190, 661 (1989).

14. G. J. Pratt and M. J. A. Smith, Polvmer, 30, 1113 (1989).

15. H. Bertilsson, B. Franzén, and J. Kubát, Plast. Rubber Process. Appl., 11, 167 (1989).

16. V. K. Stokes, Polymer, 33, 1237 (1992).

17. S. Y. Hobbs and V. K. Stokes, Polym. Eng. Sci., 31, 502 (1991).

18. P. Sanchez, P. M. Remiro, and J. Nazabal, J. Appl. Polym. Sci., 50, 995 (1993).

19. G. Montaudo, C. Puglisi, and F. Samperi, J. Polym. Sci., Part A, Polym. Chem., 31, 13 (1993).

20. D. G. Hamilton and R. R. Galluci, J. Appl. Polym. Sci., 48, 2249 (1993).

21. M. Okamoto and T. Inoue, Polymer, 35, 257 (1994).

22. H.-J. Radusch, R. Androsch, J. Vogel, J. Trempler, and S. Fakirov, Angew. Makromol. Chem., 198, 135 (1992).

23. H.-J. Radusch and R. Androsch, Angew: Makromol. Chem., 214, 179 (1994).

24. N. Wings and G. Trafara, Angew'. Makromol. Chem., 217, 91 (1994).
25. W. N. Kim and C. M. Burns, Makromol. Chem., 190, 661 (1989).

26. M. Kimura, R. S. Porter, and G. Salee, J. Polym. Sci., Polym. Phys. Ed., 21, 367 (1983).

27. A. Ausin, J. I. Eguiazábal, M. E. Muñoz, J. J. Peña, and A. Santamaria, Polym. Eng. Sci., 27, 529 (1987).

28. C. R. Desper, M. Kimura, and R. S. Porter, J. Polym. Sci., Polym. Phys. Ed., 22, 1193 (1984).

29. J. I. Eguiazábal, J. J. Iruin, M. Cortazar, and G. M. Guzman, J. Appl. Polym. Sci., 32, 5945 (1986).

30. M. Cortazar, J. J. Iruin, and J. I. Eguiazábal, Polym. Bull., 29 415 (1992)

31. M. Valero, J. J. Iruin, E. Espinosa, and M. J. Fernandez-Berridi, Polym. Commun., 31, 127 (1990).

32. E. Espinosa, M. J. Fernandez-Berridi, I. Maiza, and M. Valero, Polymer, 34, 382 (1993).

33. P. P. Huo and P. Cebe, Macromolecules, 26, 5561 (1993).

34. P. P. Huo, P. Cebe, and M. Capel, Macromolecules, 26, 4275 (1993).

35. P. P. Huo and P. Cebe, Macromolecules, 26, 3127 (1993).

36. I. Maiza, Ph. D. Thesis, University of the Basque Country, San Sebastian (Spain), September 1994.

37. J. P. Runt, X. Zhang, D. M. Miley, K. P. Gallagher, and A. Zhang, Macromolecules, 25, 3902 (1992).

38. J. Runt, C. A. Barron, X. Zhang, and S. K. Kumar, Macromolecules, 24, 346 (1991).

39. J. Runt, D. M. Miley, X. Zhang, K. P. Gallagher, K. McFeaters, and J. Fishburn, Macromolecules, 25, 1929 (1992).

40. D. M. Miley and J. Runt, Polymer, 33, 4643 (1992).

41. J. J. Iruin, J. I. Eguiazábal, and G. M. Guzman, Eur. Polym. J., 25, 1169 (1989).

42. S. M. Aharoni, J. Macromol. Sci.-Phys., B22, 813 (1984).

43. N. S. Murthy and S. M. Aharoni, Polymer, 28, 2171 (1987).

44. T. Eckel, D. Wittmann, J. Schoeps, H. Peters, and K. H. Ott, Ger. Offen. DE 3,828,690 (1990).

45. K. Yakamoto, K. Niimi, and K. Tomita, Jpn. Kokai Tokkyo Koho JP 04,239,549 [92,239,549] (1991).

46. J. Devaux, P. Godard, and J. P. Mercier, Makromol. Chem., 179 2201 (1978)

47. J. I. Eguiazábal, G. Ucar, M. Cortazar, and J. J. Iruin, Polymer, 27, 2013 (1986)

48. D. J. Meier, in "Polymer Blends and Mixtures," Series E, Vol. 89, D. J. Walsh, J. S. Higgins, and A. Maconnachie, Ed., NATO ASI Series, 1985, p 173.

49. D. R. Paul and S. Newman, Ed., "Polymer Blends," Vol. 1, Academic Press, New York, N.Y., 1978.

50. J. I. Eguiazábal, M. Cortazar, and J. J. Iruin, J. Appl. Polym. Sci., 42, 489 (1991).

51. J. M. Martinez, J. Nazabal, and J. I. Eguiazábal, J. Appl. Polym. Sci., 51, 223 (1994).

52. J. I. Eguiazábal and M. Cortázar, unpublished results. 